\title{
Exploration of Students' Ability Cultivation in Blended Teaching
}

\author{
Yumin Ge, Jinliang Zhang*, Huijuan Ran
}

School of Electrical and Electronic Engineering, North China Electric Power University, Baoding, 071000, China

*15603283615@163.com

\section{Keywords: Talent Cultivation;Blended Teaching; Online + offline; Curriculum Design}

Abstract. The construction of "Double World-class" and "New Engineering Disciplines" emphasize the importance of talent cultivation, which is difficult to break through in traditional teaching methods. Nowadays, new technology develops rapidly, and classroom teaching is not limited to teacher's instruction in class. More and more teachers choose blended teaching mode, which are "online + offline". With the help of the Internet and big data, the classroom radiates completely more different dynamic than before. More importantly, excellent curriculum design ideas are integrated into the intelligent teaching platform by teachers, and their perfect combination can stimulate students' learning potential to the greatest extent. Teaching practice has proved that successful blended teaching effectively cultivates students' multi-faceted ability and helps students become qualified builders of new age.

\section{Introduction}

The construction of world-class universities and first-class disciplines(hereinafter referred to as "Double World-class" construction) is an important mission of education development in the new era in China. With the development of the fourth industrial revolution, higher education is not only responsible for cultivating innovative and complex talents, but also plays the role of the new source of knowledge, and becomes the core force to promote the success of the industrial revolution. In the context of innovation-driven development, the reform and development of education has been upgraded to national strategy, which is an important strategic measure for the country to realize sustainable development and enhance international competitiveness." Double World-class " construction emphasizes the connotative development path of the university, putting talent training in a more important position[1]. Talent training is the top priority of education,especially.

The center of traditional teaching is teacher, and the dominant position of the teacher is highlighted in the teaching process. The main status of the students is often neglected on the contrary. What the teachers are exploring is how to "teach" a course more clearly.

Students have always blindly accepted the role of knowledge,which inevitably leads to the cultivation of students without imagination and creativity.Students tend to think that what the teacher says is of no practical use and significance, which is intended to fulfill the examination. Students simply understand and remember knowledge when they are learning. They do not know the context and application of the knowledge they have learned and do not construct knowledge constructively. They do not experience the process of thinking cultivation, such as discovery, conception, induction, etc. It leads to students' lack of creative thinking ability. In the course of learning, students have no clear learning target. Passive learning leads to lack of confidence and creativity. They are not clear about their future development.Truly outstanding workers and top innovators are fostered difficultly by such a talent training model[2].

Teachers have never interrupted exploration of teaching reform. They try to change teaching mode with new education thought and theory.However, teaching organization pattern, class activities and teaching structure are the same in essence by the limits of the traditional teaching mode. It is at most changed in teaching elements and activity composition.It is difficult to achieve substantial revolution[3]. 


\section{Blended Teaching[4-6]}

The disadvantages of traditional teaching are increasingly prominent.There are growing demands for more flexible pathways to accessing quality higher education and lifelong learning opportunities for all. Technology offers unprecedented opportunities to meet the needs and expectations of the learners[7].This makes blended teaching of "online + offline" become possible. This kind of teaching is carried out in the form of "online" and "offline".The "online" teaching is not the complement or the icing on the cake of the whole teaching activity, but the necessary activity of teaching. "Offline" teaching is not a copy of traditional classroom teaching activities, but a more in-depth teaching activity based on the early learning results of "online". The reform of blended teaching,which is no unified model, has a unified pursuit to give full play to the advantages of "online" and "offline" teaching to transform our traditional teaching.Also the excessive use of teaching in the course of classroom teaching should be changed which leads to problems such as low learning initiative, lack of cognitive participation, and excessive difference of learning outcomes among different students[8]. Blended teaching reform aims to improve students' ability and cultivate students from various angles.

\section{Design of Students' Ability Cultivation in Blended Teaching}

Blended teaching makes "teacher-centered" to "student-centered".We learn that in the process of implementing blended learning strategies, that we need to pay more attention to learning inputs, processes and assessments and how to measure personal development overall. This is not just a unilateral thing for teachers Students must also pay more time and energy than traditional teaching in order to adapt to their "center" position. Teachers and students work together to make the hybrid teaching work best. Students' learning potential is exploited to the greatest extent, which ultimately enables students to have lifelong learning ability.

\subsection{What teachers should do.}

With the new teaching concept and teaching mode, teachers have to make changes first, and must complete the course design of "online + offline" teaching mode in addition to the idea of acceptance. In the new design, each link should be set around improving students' ability. The following contents are brief examples in several aspects.

3.1.1 Improving students' ability of self-learning

"Teaching is for the sake of not teaching,"says Shengtao ye. This is the purpose of teaching, which is also the highest level that education workers pursue. At the same time, it also shows that the cultivation of self-learning ability is a crucial problem to learn knowledge well. The students' learning potential is fully excavated in the "pre-class push" link in the blended teaching, which is a good way to cultivate students' self-learning ability.

With the development of MOOC, its resources have been fragmented and photographed beautifully, which can be used as pre-class preview materials for blended teaching. It is obviously not feasible for the students themselves to find suitable preview material when facing with abundant MOOC resources online. First of all, it will take up a lot of students' time. Secondly, students' choice is not necessarily the most appropriate. So teachers are required to do the work. The selected video data according to the content of next class is sent to students online before class(the video length should be less than 10 minutes). Students complete the preview by watching the video. In addition to students' self-learning ability is exercised, one of the other benefits is that their knowledge reserves are close to each other in class, which is conducive to organize effective discussion. Discussion is also important to cultivate students' learning ability.

3.1.2 Improving the students' ability of thinking

Heuristic teaching should be adopted in blended teaching. In class, students should give full play to their subjectivity, so as to enhance students' participation in classroom, inspire students to think, ask questions and solve problems together. With the help of intelligent teaching platform, students are mobilized to think by using bullet screens, racing to be the first to answer a question and random quiz. 
Teachers should pay attention to the reasonable distribution of difficult and easy problems, which makes students learn to study and be willing to think.

\subsubsection{Improving students' ability of innovation}

New Engineering Disciplines points out that "emerging industries and new economy need...greatly innovative... and highly qualified "New Engineering Disciplines 'talents' ". The importance of innovation ability can be seen in the talent cultivation. In blended teaching, teachers should pay attention to combining practical engineering application with theoretical knowledge. It turns out that students look forward to it because it is the practical application of the knowledge learned in class. It is helpless only with listening and expanding horizons if students feel it's none of their business. Therefore, questions should be asked by teachers in this way: "There is a practical problem of engineering... Do you think we have a solution to this problem with the knowledge we've learned?..."

Even the students' thoughts and ideas are absurd and impractical, they are precious.Because it is cultivating students' innovative thinking and innovative consciousness indeed[9].

3.1.4 Improving students' ability of discovering, analying and solving problems

There is a famous saying among the teachers and students of Harvard University: One of the real objects of education is to have a man in the condition of continually asking questions.

Full discussion should be set to students during conducting blended teaching.Let students find problems in the discussion, analyze the problems by self-reflection or group communication or teachers' guidance, and finally solve the problem by students themselves. This process allows students to develop the habit of exploring, the spirit of cooperation, the ability to express and construct strong self-confidence. This will not only improve students' learning ability, but also help them gain a sense of accomplishment,which increase their interest in learning. All difficulties will become easier to overcome because of interest, which is the best teacher.

3.1.5 Improving students' ability of inductive and deductive

Induction is to find out the internal relationship and conclude their common points from a number of phenomena. That is the general truth. It is written down in the form of conclusion, which reflects the process of guessing and discovering problems. Deductive method is an argument method which deduces individual conclusion from generality conclusion or general case. It is the whole process of rational thinking from hypothesis to knowledge system to scientific language, which is the main method to expand the knowledge system and reveal the internal relation of knowledge. It is important for students to master such a method undoubtedly.

Special attention should be paid to the training of students' deductive ability in blended teaching. After the explanation of a series of related knowledge points, students should be asked to summarize after class. It can be a mind map, a form,or a poetry. This is the process of induction, and it is a good way to test students whether they have mastered the knowledge they have learned in class. When learning new knowledge, students should be guided by teachers to assume the conclusion on the basis of the old knowledge and then carry on the learning and verification. Students' deductive ability is exercised.

\subsection{What students should do.}

The new method of blended teaching means greater academic pressure and more learning tests for students because every discussion before class they are asked to do some reading and answer questions on the internet,which is helpful for teachers to master the progress of different students. In this transition, students will complain, but they also admit to learning more[10].

In the process of blended teaching, students will fall behind in the discussion if they don't cooperate with the teacher in the link of preview because of lazy. Then a series of links teachers have carefully set up to improve their students' abilities can be counterproductive instead of playing its due role.

Therefore, students should be required to strengthen their management and restraint,improve their own quality and move towards higher goals. Never give up when encounter difficulties and setbacks in the process. Be good at discovering self-progress. Step by step and persistence is victory. 


\section{Conclusion}

The education community has reached a consensus on " give it fish" or " teach it to fish". The purpose of education is to enable students to master the methods and abilities of acquiring knowledge. Blended teaching can form a continuous assessment of students before, during and after class.The students' ability of self-study, innovation and inductive deduction are comprehensively cultivated. The teaching concept of " making the student's learning ability center " is carried out in the whole teaching process to help students grow into excellent talents and adapt to the construction and development of the new era.

\section{Acknowledgement}

This paper is subsidized by:

(1)research and practice of higher education teaching reform project in Hebei province(research and practice of hybrid teaching in circuit course centered on the improvement of students' ability, 2017GJJG211);

(2) North China Electric Power University (Baoding) common course quality improvement project, and North China Electric Power University (Baoding) excellent young teacher teaching support scheme.

\section{References}

[1] Lu wei, Ji bo. The Construction of "Student-centered" Adaptive Growth System--, "Stanford 2025 project" its Enlightenment to China's "Double World-class" Construction[J]. World Education Information, 2018(9).

[2] Zhong Shaochun. Smart Education-- Education that Should Be Pursued. Ministry of Education its Support Technology Engineering Center of Digital Learning, 2018-5-10.

[3] Li manli, Zhang yu, Ye fugui, et al. Investigation of Pedagogy of Decoding MOOC for Large-scale Open Online Courses [M]. Beijing:Tsinghua University Press, 2013.

[4]Wu ning, Fang Chenchen, Ren Yanfei. Mixed Teaching Design and Effect Analysis Based on SPOC in Large Class Teaching Environment [J]. China University Teaching, 2016.

[5]Zhan desheng. The Implementation Plan in the Mixed Teaching Reform of "University Computer", "MOOC+SPOCs+ Flipped Classroom" [J]. Computer Education, 2016 (1).

[6]Su xiaohong, Zhao lingling, ye Lin, et al. Exploration and Practice of Hybrid Teaching Based on MOOC+SPOC [J]. China University Teaching, 2015 (7).

[7]Gwang-Jo Kim, Lim, Cher Ping, Wang, Tianchong,etc. Blended Learning for Quality Higher Education: Selected Case Studies on Implementation from Asia-Pacific.2016.

[8]Cao dianbo. Mixed Teaching Reform. Information Education Network, 2018-01-03.

[9] Edited by yu xin-jie. Student-Centered Teaching and Learning: Implementation of Flipped Classroom with MOOC Resources [M]. Beijing: Higher Education Press, 2017.

[10]Jin wei, Cai mei. "Refinement" Reconstruction of American College in Large Courses. China Education, 2017-12-22: 5th edition. 